\title{
Implementation of simulation for training minimally invasive surgery*
}

\author{
H.W.R. Schreuder, G. Oei, M. Maas, J.C.C. Borleffs, M.P. Schijven
}

\begin{abstract}
Summary
Minimal invasive techniques are rapidly becoming standard of surgical technique for many surgical procedures. To train the skills necessary to apply these techniques, box-trainers and/or inanimate models may be used, but these trainers lack the possibility of inherent objective classification of results. In the last decade virtual reality (VR) trainers were introduced for training minimal invasive techniques. Minimally Invasive Surgery (MIS) is, by nature, very suitable for this type of training. The specific psychomotor skills and eye-hand coordination needed for MIS can be mastered largely using VR simulation techniques. It is also possible to transfer skills learned on a simulator to real operations, resulting in error reduction and shortening of procedural operating time. Authors aim to enlighten the process of gaining acceptance in the Netherlands for novel training techniques. The Dutch Societies of Surgery, Obstetrics and Gynecology and Urology each developed individual training curricula for MIS using simulation techniques, to be implemented in daily practice. The ultimate goal is to improve patient safety. The authors outline the opinions of actors involved such as: different simulators, surgical trainees, surgeons, surgical societies, hospital boards, government and the public. The actual implementation of nationwide training curricula for MIS is, however, a challenging step. (Schreuder HWR, Oei G, Maas M, Borleffs JCC, Schijven MP. Implementation of simulation for traning minimally invasive surgery. Netherlands Journal of Medical Education 2011;30(5): 206-220.)
\end{abstract}

\section{Practice points}

- Simulator training cannot stand on its own, but needs to be a part of a training curriculum.

- A simulator on itself is not 'valid'. It is the way it is used in a particular teaching curriculum that determines its validity for the cause.

- Proficiency based skills training leads to less errors in the operating room and reduces operating time.

- Well-developed training programs must be demanded by the government, developed and defined by the medical societies and facilitated by the hospitals.

- Allocated time for training and consequences when not fulfilling the training requirements stimulate skills training.

\footnotetext{
* Dit artikel verscheen eerder in Med Teach 2011;33(2):105-115.
} 


\section{Introduction}

In healthcare, as in society at large, computer aided implementation of innovations has become daily practice. Computer-aided scanning by MRI, (PET)CT and other technical modalities in radiology; devicedriven steering mechanisms in endoscopy, self-employable stenting devices in cardiology and vascular surgery, full robotic surgical systems in laparoscopic surgery are examples of such advances. Laparoscopic surgery may the area in which computeraided implementations are most prominently visible, as this young specialty has always been driven by technological innovation and has been an early adopter of novel techniques, from its start.

In the twenty-first century, minimally invasive surgical (MIS) techniques have become the standard of surgical care for many patients. Unlike open surgery, MIS is, by its nature, a technique that is very suitable for simulation-based training. The specific psychomotor skills and eye-hand coordination needed for this type of surgery can be trained easily through simulation. ${ }^{1-2}$ For skills training, box-trainers or computer-enhanced trainers may be used, but the last decade new virtual reality trainers have been introduced for training minimally invasive techniques. Nowadays, simulation training, often enhanced using virtual reality techniques is used for a wide range of training purposes: laparoscopy, ${ }^{3}$ robot-assisted surgery, ${ }^{4}$ endoscopy, ${ }^{5}$ cystoscopy, ${ }^{6}$ hysteroscopy ${ }^{7}$ and intervention radiology. ${ }^{8}$ It is possible to transfer skills learned on a simulator to real operations, leading to less errors and shorter operating time. ${ }^{9-10}$ Recently, e-learning programs and 'Serious Games' for MIS, embedding a training curriculum, step-by-step approaches, encouraging the making and solving of mistakes and a diversity of storylines have been introduced. ${ }^{11}$
The traditional 'apprentice-mentor' education model is commonly used to learn surgical skills. In this model, surgery is largely mastered through observation, followed by imitation of the actions of the mentor. For MIS, this model is challenged due to several factors. Reduced working hours and increased numbers of residents on the work floor results in less exposure to surgery. Constant innovation in treatment modalities to be learnt by the mentors reduces the number of surgical procedures available for teaching and learning of apprentices. Furthermore, the continuous pressure on reducing operation time in order to be more cost effective and the ethical aspects to limit patient morbidity, to reduce complications and to maximize patient safety drive the public awareness and demand professional responsibility. In 2008, after publishing their report entitled "Risks minimally invasive surgery underestimated",12 the Dutch government demanded strict rules for MIS. As a result, requirements for skills training were defined by the surgical societies, and hospitals were obliged to implement these requirements in their training programs. Nowadays every resident in surgical training and every surgeon needs to demonstrate that he or she possesses minimum standards of skill before operating on patients. Performing MIS without demonstrated competence is considered unethical and unprofessional. In this view, it has become mandatory to establish objective validated measurable levels of practical skills prior to start MIS on patients. Since these skills can be mastered using simulation techniques, it is not surprising that MIS has taken the lead in using simulation applications for training. ${ }^{9}$ The Dutch Societies of Surgery, Obstetrics and Gynecology and Urology each developed a training curriculum for MIS, to be implemented in daily practice. ${ }^{13}$ The implementa- 
tion of a nationwide trainings curriculum for MIS will be a next step. The Dutch Society for Simulation in Healthcare (DSSH) ${ }^{14}$ provides a platform to share experiences, which will accelerate a nationwide implementation of proficiency-based training curricula. This paper describes current developments regarding MIS training and illustrates the Dutch experiences with development and implementation of training curricula for MIS.

\section{Simulation in minimally invasive surgery}

Specific psychomotor skills are needed to perform MIS. Hand-eye coordination, adaptation from 3-dimensions to a 2-dimensional screen, dealing with the fulcrum effect--the need for the surgeons to move their hand in the opposite direction in which the tip of the instrument intends to go--acquiring fine motor skills to handle the long instruments without proper tactile feedback--the sense of touch when applying force--these are all skills which the future laparoscopist needs to master. ${ }^{1}$ Simulation has proven to be a proper tool to learn and train these skills. ${ }^{9}{ }^{15}$ Several simulation modalities can be used for learning and training MIS. There are different animal models, box/video trainers and virtual reality simulators to choose from. In addition, 'serious gaming' has entered the field of minimally invasive surgical training as well.

\section{Box training}

Box and video trainers provide a relatively easy and cheap simulation model for MIS. These platforms usually consist of a normal laparoscopic tower with a training box, but are also available as stand alone units with an inbuilt camera (Figure 1). For the acquisition of basic laparoscopic skills box trainers are equally effective as VR trainers. ${ }^{16}$ Box trainers provide realistic haptic feed- back, yet objective assessment is difficult and an expert observer must be available to asses performance. The last decade different box/video trainer models and exercises have been developed. When using box trainers it is important to use validated exercises with a proper training goal. An overview of validated exercises is given in Table 1. The Fundamentals of Laparoscopic Surgery (FLS) program ${ }^{17}$ implemented existing box trainer exercises in its program. ${ }^{18}$ For the FLS program a special portable box trainer with an inbuilt camera was developed. Performance on this box trainer correlated well with objective assessment of intraoperative performance. ${ }^{19}$ For training MIS at home, portable and inexpensive box trainers can be used. ${ }^{20}$

\section{Virtual reality training}

Virtual reality (VR) simulators (Figure 2) provide a safe and standardized environment to practice specific skills for MIS and have the surplus value of being able to measure performance outcome of the trainee simultaneously and objectively. ${ }^{21}$ Compared to box/video trainers, VR simulators are at least as effective and can supplement standard laparoscopic box/video training. ${ }^{3}$ Unlike box trainers, most VR simulators lack realistic tactile feedback. To overcome this problem, augmented reality laparoscopic simulators have been developed. These training devices provide both objective assessment after performance and realistic tactile feedback. ${ }^{22}$ In the last decade, several VR simulators have been developed and validated (Table 2). In contrast to box trainers, VR trainers have the capacity to train both basic skills as well as simulate full procedural surgical tasks (e.g. the laparoscopic salpingectomy or laparoscopic cholecystectomy). These innovations could be used in addition to box trainers to train skills needed in more advanced surgical procedures. VR training 
improves overall laparoscopic surgical skills and the acquired skills on a VR simulator are, in itself, not procedure specific. ${ }^{23}$ There is a significant correlation between operative performance and psychomotor performance on VR reality simulators. ${ }^{24}$ Above all the newly learned skills on the VR simulator are transferable to actual laparoscopic operations in human patients. ${ }^{925}$

\section{E-learning es serious gaming}

In the last decade, the use of e-learning has rapidly grown. Many students browse the internet routinely, for search, play and information purposes. In fact, these elements are needed for successful learning. In most modern medical curricula, e-learning is introduced to satisfy this need for modern information gathering. Traditional classroom problem based learning can also be transferred to a virtual environment, like in Second Life, thus enabling a modern yet familiar environment for problem based learning. ${ }^{26}$ Applications for MIS have, likewise, been initiated. Web based applications like the World Electronic Book of Surgery (WebSurg) ${ }^{27}$ are widely used in the surgical community. This online learning portal contains a large collection of streaming and downloadable HD quality videos of surgical procedures; combined with howto step-by-step surgical teaching guidelines to aid the implementation of MIS procedures for various surgical disciplines.

Recently, the first interactive e-learning program for MIS was introduced. The 'Simpraxis' ${ }^{\mathrm{TM}}$ Laparoscopic Cholecystectomy Trainer' is a customizable interactive simulation software training platform for cognitive learning of surgical procedures. ${ }^{28}$ It integrates multimedia (such as video, 3D models, radiology, illustrations, text, and still images, all captured from live procedures) and combines them with expert cognitive training pedagogy to create a powerful simulation of the procedure (Figure 3). All these elements combined simulate the feeling of performing the actual physical procedure while only using a computer. There is a detailed assessment of performance and one should complete the whole module within a set score to pass. The e-learning module is certified by the Accreditation Council for Continuing Medical Education of the USA and in this way it is possible to earn CME credits.

Besides e-learning, there is also a place for 'Serious Gaming' in learning MIS. Since there is a positive correlation between video game skills and laparoscopic surgical skills, video games may be a practical training tool to help surgeons. ${ }^{29}$ Badurdeen et al. demonstrated a skill overlap between certain games for the Nintendo Wii ${ }^{\mathrm{TM}}$ gaming console and basic laparoscopic skill tasks. ${ }^{30}$ This gaming console is relatively inexpensive, allows natural hand movements similar to those performed in laparoscopy and can be effectively used as a 'take-home' simulator. ${ }^{31}$ Another application of serious gaming is creating an online competition for VR simulation training, which may enhance voluntary skills training. ${ }^{11}$

\section{Animal models}

Animal models, mainly pig models, have the advantage of simulating tissue handling and clinical scenario's better then any other simulation model and are still frequently used for procedure and device training in-company supported programs. Due to financial, legal and ethical reasons, animal model training is slowly being replaced by other simulation models. With the new generation of VR simulators this shift is possible without compromising on the quality of the skills training.

\section{Other simulators in MIS}

Recently, new VR simulators for other fields of MIS were developed. A new area of 
MIS is robot-assisted laparoscopic surgery. ${ }^{32}$ This type of surgery is becoming more and more accepted and there is a growing need for training residents and fellow's in this type of surgery. Two new VR simulators for robotic surgery are recently validated and face and construct validity were established. ${ }^{43}$ In the field of gynecology, hysteroscopy is an important minimally invasive tool to treat abnormalities inside the uterine cavity. Training hysteroscopy is traditionally done using a porcine bladder to simulate the cavity and perform resections, which has been shown to improve resident performance. ${ }^{34}$ In 2009, a VR simulator especially for hysteroscopy was introduced and validated. ${ }^{7}$ The use of simulation is nowadays well established in training MIS in most areas. For open surgery simulators are still difficult to develop.

\section{Teamtraining}

Training how to act in the operation theatre or emergency room generally happens on individual basis. In practice, however, a hospital patient is treated by a multidisciplinary team. It has been shown that giving multidisciplinary team training to clinical teams leads to improvements in dealing with fatigue, teambuilding, communication, recognizing dangerous situations, decision-making and providing feedback. ${ }^{35}$ For the purpose of such team training specific full body simulators are developed. These high fidelity patient simulators can be fully programmed to simulate an acute disorder. Scenarios can be tailored to specific target groups. Participants can be tested on their individual clinical skills and competence to work together under pressure as a team. Training in a medical simulation centre with high fidelity simulators offers the opportunity to train rare emergency scenarios under standardized conditions and give targeted feedback on functioning as indi- vidual and team. Training of health care teams in emergency situations promotes cooperation and reduces the number of communication errors. ${ }^{36}$ Therefore residents should not only be trained in medical knowledge and skills, but also in collaboration and communication, two other competencies of the CanMED model. ${ }^{37}$ Eighty percent of the time spent in a recently established multidisciplinary Gyn \& OB simulation training focuses on communication and collaboration. The concept can easily be transferred to other specialties and multidisciplinary team training for surgical residents will be introduced in 2010 .

\section{Current state of implementation of skills training for minimally invasive surgery in the Netherlands}

In the Netherlands MIS is professionally organized. The Dutch Society of Surgery, Dutch Society of Obstetrics and Gynecology and the Dutch Society of Urology each have their own working group on MIS, together combined and represented by the Dutch Society of Endoscopic Surgery. In November 2007, the Dutch Inspectorate for Healthcare published a firm report entitled "Risks minimally invasive surgery underestimated", expressing its concern regarding endoscopic surgery and patient safety in the Netherlands. ${ }^{12}$ Training in MIS was found to be inadequately structured and implemented. A need for national standardized training programs for MIS, with strict criteria, was stressed and firm recommendations were stated. Furthermore, a number of nationally endorsed hospital interventions were demanded; many of which surpassing specialist-specific boundaries. In reaction, various working groups of the respective clinical medical specialties started developing structured, competency-based MIS curricula including appropriate outcome evaluation. 
Table 1. Validated box/video trainers for minimally invasive laparoscopic surgery.

\begin{tabular}{|c|c|c|c|c|}
\hline Name & Trainer type & $\begin{array}{c}\text { Face } \\
\text { Validity }\end{array}$ & $\begin{array}{l}\text { Construct } \\
\text { Validity }\end{array}$ & $\begin{array}{l}\text { Predictive } \\
\text { Validity }\end{array}$ \\
\hline $\begin{array}{l}\text { McGill Inanimate System for Training and } \\
\text { Evaluations of Laparoscopic Skills (MISTELS) }\end{array}$ & Box trainer & yes & yes & yes \\
\hline Fundamentals of laparoscopic Surgery (FLS) ${ }^{18}$ & Box trainer & yes & yes & yes \\
\hline Yale Laparoscopic Skills and Suturing & Laparoscopic & no & yes & no \\
\hline Programme (YLSSP) $)^{49}$ & Surgical trainer & & & \\
\hline Southwestern videotrainerstations ${ }^{15}$ & Videotrainer & yes & yes & yes \\
\hline SIMULAB $1^{50}$ & $\begin{array}{l}\text { LapTrainer with } \\
\text { SimuVision LTS-10 }\end{array}$ & no & yes & no \\
\hline SIMULAB $2^{51}$ & $\begin{array}{l}\text { LapTrainer with } \\
\text { SimuVision LTS-10 }\end{array}$ & no & yes & no \\
\hline SIMULAB $3^{52}$ & $\begin{array}{l}\text { LapTrainer with } \\
\text { SimuVision LTS-10 }\end{array}$ & yes & yes & no \\
\hline $\begin{array}{l}\text { Laparoscopic Skills Testing and Training } \\
\text { (LASTT) })^{53}\end{array}$ & Szabo trainer box & yes & yes & no \\
\hline $\begin{array}{l}\text { Legacy Inanimate System for Laparoscopic } \\
\text { Team Training (LISETT) })^{54}\end{array}$ & Ethicon Laptrainer & no & yes & no \\
\hline Pelv-Sim 55 & Pelv-Sim box trainer & no & yes & no \\
\hline Lentz ( 6 tasks developed by author) ${ }^{56}$ & $\begin{array}{l}\text { Mirrored trainer and } \\
\text { box trainer }\end{array}$ & no & yes & no \\
\hline Black ( 5 tasks, developed by author) ${ }^{57}$ & Video trainer & no & yes & no \\
\hline Kolkman ( 5 tasks developed by author $)^{58}$ & Box trainer & no & yes & no \\
\hline Clevin ( 5 tasks developed by author) ${ }^{59}$ & Box trainer & no & yes & no \\
\hline Risucci $2001^{60}$ & Box trainer & no & yes & no \\
\hline
\end{tabular}

\section{General surgery}

A standardized surgical training protocol for MIS was developed by the Dutch Society of Endoscopic Surgery and the Working Group for Endoscopic Surgery, residing under the Dutch Society for Surgery. A pre-set level of knowledge is required and further development of laparoscopic knowhow and skills embedded in a 3-step curriculum (Table 3 ). This level-of-skill must be tested and periodically re-evaluated. As a consequence, if a resident is no longer 
Table 2. Validated virtual reality simulators for minimally invasive laparoscopic surgery.

\begin{tabular}{|c|c|c|c|c|c|c|c|c|}
\hline VR Simulator & & $\begin{array}{c}\text { Construct } \\
\text { validity }\end{array}$ & $\begin{array}{c}\text { Predictive } \\
\text { validity }\end{array}$ & $\begin{array}{c}\text { Haptic } \\
\text { feedback }\end{array}$ & $\begin{array}{l}\text { Basic } \\
\text { skills }\end{array}$ & $\begin{array}{c}\text { Procedural } \\
\text { task }\end{array}$ & Curriculum & $\begin{array}{c}\text { Team } \\
\text { training }\end{array}$ \\
\hline Simendo $^{61}$ & Laparoscopy & yes & no & no & yes & no & yes & yes \\
\hline ProMiss $^{62}$ & Laparoscopy & yes & no & yes & yes & yes & yes & yes \\
\hline MIST-VR ${ }^{2}$ & Laparoscopy & yes & yes & no & yes & no & yes & no \\
\hline Procedicus KSA ${ }^{63}$ & Laparoscopy & yes & no & yes & yes & no & yes & no \\
\hline Lap Mentor ${ }^{64}$ & Laparoscopy & yes & yes & yes & yes & yes & no & no \\
\hline Lap Sim 65 & Laparoscopy & yes & yes & no & yes & yes & yes & yes \\
\hline EndoTower ${ }^{66}$ & Laparoscopy & yes & no & no & yes & no & no & no \\
\hline Xitact LS $500^{67}$ & Laparoscopy & yes & yes & yes & yes & yes & no & no \\
\hline SepSurgery ${ }^{68}$ & Laparoscopy & yes & no & no & yes & yes & no & no \\
\hline Lap-VR ${ }^{69}$ & Laparoscopy & yes & no & yes & yes & yes & yes & yes \\
\hline dV-Trainer ${ }^{4}$ & $\begin{array}{l}\text { Robotic } \\
\text { surgery }\end{array}$ & yes & no & no & yes & no & no & no \\
\hline $\operatorname{RoSS}^{33}$ & $\begin{array}{l}\text { Robotic } \\
\text { surgery }\end{array}$ & yes & no & no & yes & no & no & no \\
\hline
\end{tabular}

able to pass a certain level of knowledge or skill, he or she is no longer allowed in the clinical surgical laparoscopic setting as a first operator on patients. More precisely, every resident in training for surgery must follow this curriculum and pass the test before embarking on patient surgery and must have the opportunity to train repeatedly on a permanently available and functional laparoscopic training setting. Ideally, a supervising, certified surgeon is present to correct posture and problems of the training environment. The nationwide implementation of this three step curriculum is not an easy process, as many regions have their own programs. Nevertheless, it is to be expected that these programs will adhere to the standardized training protocol in the near future as it is the framework against which these programs will be tested by the government.

\section{Gynecology}

The Dutch Society of Gynecological Endoscopy developed recommendations for training and learning MIS early 2008, which were accepted by the national society. In this report, a format for a structured competence based curriculum for learning MIS is described (Table 3). The hospitals were obliged to have a box trainer or a VR trainer. In gynecology the complexity of laparoscopic procedures is defined by the European Society of Gynecologic Endoscopy. ${ }^{38}$ In the six years of training, skills up to level II need to be acquired. The courses are organized regionally, on a small scale, to secure enough practical exposure and personal feedback for the participants. Practical training on simulators is mainly done in the separate teaching hospitals. Unfortunately, the availability of skills labs and simulation facilities still varies among the different hospitals. This hampers the implementation process and can make passing a simulation exam before starting surgery difficult. In some regions, a portfolio for laparoscopic surgery is used. This enables a good insight in the progression of the resident. 
Table 3. Separate training programs for MIS training in the Netherlands.

\section{General Surgery}

Three step curriculum to be completed in the first two years of training

- Step 1

- Staff endorsed knowledge module

- Step 2

- Validated laparoscopic psychomotor skills curriculum. This can be box/video trainer, VR trainer or porcine ex-vivo gallbladder or a combination.

- Only after completion of step 1 and 2 progress to step 3

- Step 3

- Living anaesthetized pig model for teaching laparoscopic surgical steps and procedures

\section{Gynecology}

General format to be filled in regional

- Year 1

- Combined two day course with exam (theory, practical skills)

- Regular competence based practical skills training in own hospital, validated local exam to be past before starting with laparoscopy

- Starting with level I (easy) procedures

- Year 2-4

- Regular assessment of skills in operating room and skills lab using OSATS

- With gaining experience starting with level II (moderate) procedures

- Retention of skills measured by repeating simulator exam with increasing difficulty every 6-12 months

- Year 5-6

- Combined two day advanced course with exam (theory and practical skills) in year 5

- Regular assessment of skills in operating room and skills lab using OSATS

- Retention of skills measured by repeating simulator exam with increasing difficulty every 6-12 months

\section{Urology}

Competence based Program "Basic Laparoscopic Urological Skills": including

- Knowledge exam

- Practical exam laparoscopic skills exam

- Abstracted from the FLS training model with two new exercises developed more specific for urology

- Yearly nationwide examination

Notes: OSATS = Objective Structured Assessment of Technical Skills ${ }^{70}$

\section{Urology}

The Dutch Foundation of Endourology forms the platform for urological endoscopic skills training. A large national project "Training in Urology" with a focus on the development of extended educational programs, using validated training models was started in 2007. A special module "Basic Laparoscopic Urological Skills" for training MIS in urology was developed (Table 3). Residents receive the program when they start training and can start the basic skills training in their own hospital.

\section{Skills curricula and skills laboratory: common denominators and differences}

Providing sophisticated simulators to hospitals is not enough to assure that trainees 
will start training. Simulator training should be incorporated in an obligatory training program. If this does not happen, most trainees will simply not be sufficiently motivated to train. ${ }^{39}$ To be optimally effective, the simulator training should be incorporated not only in an obligatory, but also in a competency-based training program. These programs are based on the progression of the trainee rather than on parameters measuring merely efficiency (such as 'path length' or time spent on training). This is important as we know now that the rate of progression, as reflected in the individual learning curve, may vary considerably among trainees. ${ }^{40}$

Surgical skill acquisition can be subdivided in a three stage progression model: a cognitive stage (knowledge), an associative stage (technical skill) and an autonomous stage (adequate judgment). All three stages need to be addressed in a good surgical skills curriculum. ${ }^{41}$ The practical surgical skill curricula developed in the last decade mainly focus on the associative stage. Some authors describe a more general development of a surgical skills curriculum in which an integrated approach of all three stages is well documented. Gallagher et al. describe an eight step approach to set up a surgical skills curriculum regardless of specialty program, including 1) didactic teaching, 2) instruction, 3) common errors, 4) test of didactic information, 5) technical skills training, 6) provide immediate feedback, 7) provide summative feedback, 8) include repeated trials, learning curve and a proficiency performance goal. ${ }^{42}$ McClusky et al. give a good description of a sequential, progressive, modular surgical skills curriculum. The modular system distinguishes five different modules; Module 1, knowledge acquisition, Module 2, psychomotor assessment \& initial acquisition, Module 3, integration of knowledge \& psychomotor skills, Module 4, supervised 're- al-world' application, Module 5, mastery. ${ }^{43}$ With such a stepwise or modular system in mind, it is possible to develop proficiency or competence based surgical skills curricula for all type of procedures. Depending on the goal of the curriculum, different simulators or specific tasks, as long they themselves are validated, may be incorporated in the curriculum.

When bringing a well-designed surgical skills curriculum into practice, an appropriate environment such as a skills centre is essential (Figure 4). Before setting up a skills centre it is important to define the mission of the centre. Definition of the purpose(s) and identification of the stakeholders (e.g. one specialty or more specialties) and resources are important early on in its development. The personnel, space resources and equipment purchased should be tailored by the curricular needs and not the other way around..$^{44}$ If not, one could end up with an expensive empty shell, being a beautifully equipped, empty space with a disappointed staff to run it.

\section{Discussion}

Developing and implementing a nation wide training program for MIS is a very complex and demanding process. The guidelines, derived from the report of the Dutch Inspectorate of Healthcare in 2007, enforced the development of structured competency-based training programs in surgery, obstetrics and gynecology and urology. ${ }^{12}$ These three front running subspecialties using MIS now have their own program on paper, but they all experience problems with nationwide implementation of the programs. Facilities are not always properly equipped, teaching staff is not always willing or able to teach such a curriculum, and residents are often too occupied with daily practice core activities to train. ${ }^{45}$ Eventually, most often human barriers are the hardest to overcome. The NVMO 
special interest group in Skills \& Simulation and the DSSH are building bridges between the different subspecialties for optimal use of resources and to enhance standardization of training programs.

In all programs, simulation based training to a certain level of competence is stated to be mandatory before the trainee can start MIS on patients as a first operator. To implement and enforce this, a change in culture of residents and staff is required. Without additional support from the department chair and institution board of the hospital, this is almost a mission impossible. A key factor is the motivation of staff and trainees, who all should commit themselves to the agreed training program. Trainee motivation may be influenced to a certain extent. Internal motivation of trainees varies from person to person and is difficult to change, but external motivation of trainees can be influenced by staff and program directors, by organizing time to train during working hours, setting-up a competition, giving feedback, providing a small and easy accessible skills lab in the residents room and so on. Department chairs and program directors should communicate the skills program to all involved and should create the allocated training time during working hours; instead of trusting trainees to train by themselves in their offduty hours. ${ }^{41}{ }^{45}$ It should be clear what is expected from trainees and staff. Furthermore, staff must agree on the issue not to allow residents to operate on patients unless they have reached the set level of competence. The dedication and quality of staff regarding MIS training could be of decisive importance for the success of a nationwide training program. The institutional board must facilitate the initiative in terms of offering space and resource for the initiative. The government, at last, through defining rules and checking the current status of implementation, is the key in enforcing timely action on the proper implementation of proposed nationwide curricula and those institutes lacking to do so.

We know that many factors can affect the effectiveness of a surgical skills curriculum for MIS. When creating a skills curriculum, one should take these factors into account, in order to optimize skills acquisition and improve trainee readiness for the operating room. Important factors are: deliberate practice, trainee motivation, performance feedback, task demonstration, practice distribution, task difficulty, practice variability, proficiency-based training, and performance assessment. ${ }^{46}$ To enhance self directed learning and to evaluate results, a portfolio for the trainee is a useful tool. ${ }^{47}$ In the Netherlands, a separate section for MIS training was introduced in the subspecialty portfolios of general surgery and gynecology.

When building a skills laboratory, it is important to adjust or equip the skills laboratory based on the needs of the people working near to it, the demands of the institute in which it is hosted, and the skills curricula set by the different professional embodiments. In this way skills training for MIS can be cost-effective. ${ }^{48}$

\section{Conclusions}

Simulation based training is effective for training MIS and the learned skills have shown to be transferable into the operating room, leading to improvement of patient safety. Simulators should not be used on their own, but should be incorporated in a competency- or proficiency- based laparoscopic training curriculum, using criteria set by the professional community, to be enforced by the hospital board. To implement such a curriculum, good cooperation between institutional board, program director, department chair, medical staff and trainees is thus essential. In the Netherlands the subspecialties of Surgery, Obstet- 
rics and Gynecology and Urology each developed a training curriculum for MIS. These subspecialties are now challenged with the implementation of the training curricula and notice that funding, motivation and commitment are crucial factors. Perhaps most crucial is, however, the human factor. Different viewpoints on proposed national curricula are of course important but on the other side, cause serious delay in implementation. A better approach would be to start the implementation once agreed upon by the respective societies, and sharpen the curricula using careful and timely evaluation. The Dutch Society for Simulation in Healthcare, a fast growing national simulation platform, provides a excellent platform for communication and sharing knowledge between the different subspecialties, medical educators and hospital managers as far as it concerns simulation based training.

\section{Acknowledgements}

The authors thank Dr. ir. Frank Delbressine for reading the outline and Barbara Schout, MD, $\mathrm{PhD}$, for providing the urology information.

\section{References}

1. Derossis AM, Bothwell J, Sigman HH, Fried GM. The Effect of Practice on Performance in a Laparoscopic Simulator. Surg Endosc 1998;12:1117-20.

2. Grantcharov TP, Bardram L, Funch-Jensen P, Rosenberg J. Learning Curves and Impact of Previous Operative Experience on Performance on a Virtual Reality Simulator to Test Laparoscopic Surgical Skills. Am J Surg 2003;185:146-9.

3. Gurusamy K, Aggarwal R, Palanivelu L, Davidson BR. Systematic Review of Randomized Controlled Trials on the Effectiveness of Virtual Reality Training for Laparoscopic Surgery. Br J Surg 2008;95: 1088-97.

4. Kenney PA, Wszolek MF, Gould JJ, Libertino JA, Moinzadeh A. Face, Content, and Construct Validity of DV-Trainer, a Novel Virtual Reality Simulator for Robotic Surgery. Urology 2009;73:1288-92.

5. Bittner JG, Mellinger JD, Imam T, Schade RR, Macfadyen BV, Jr. Face and Construct Validity of a Computer-Based Virtual Reality Simulator for ERCP. Gastrointest Endosc 2010;71:357-64.
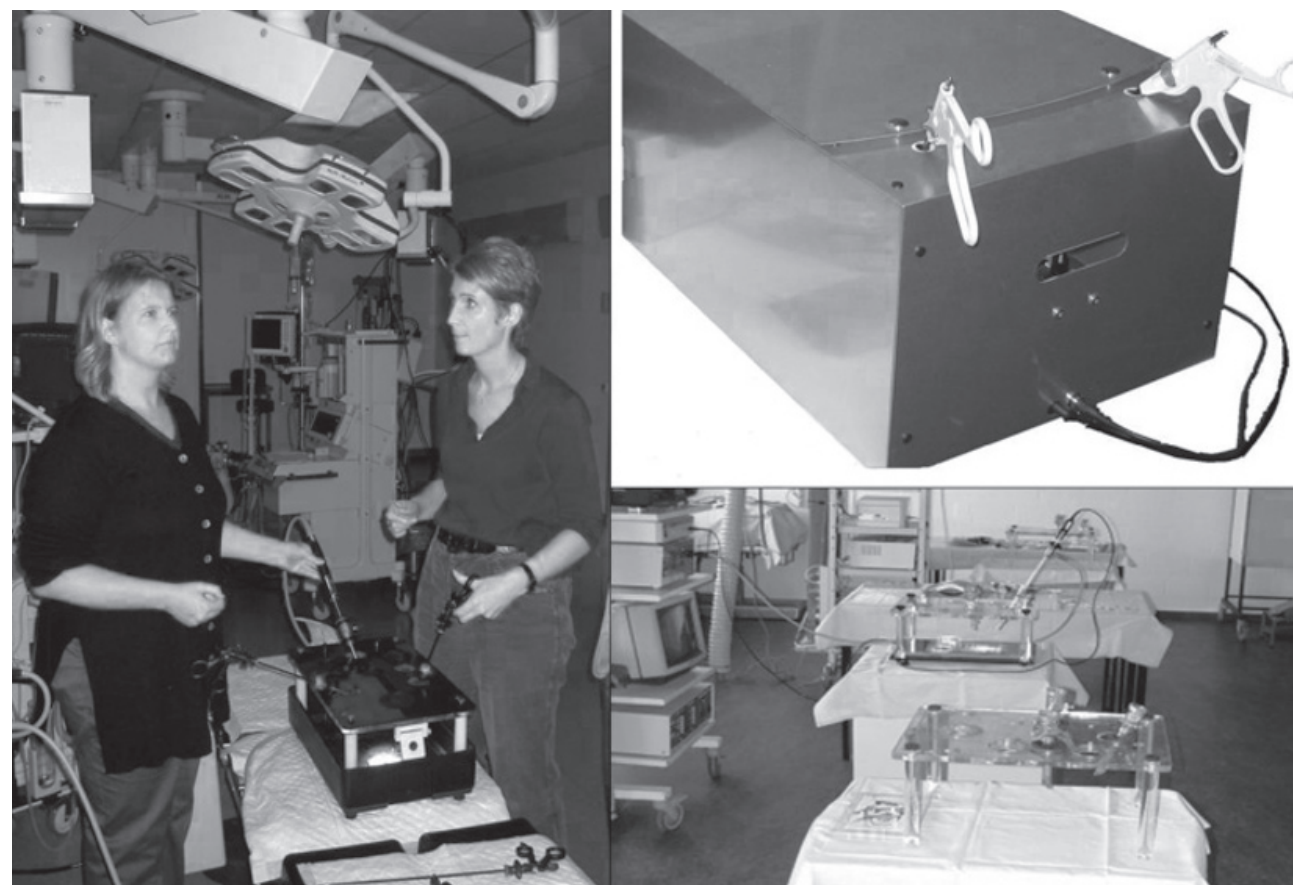

Figure 1. Box trainers for training MIS. 

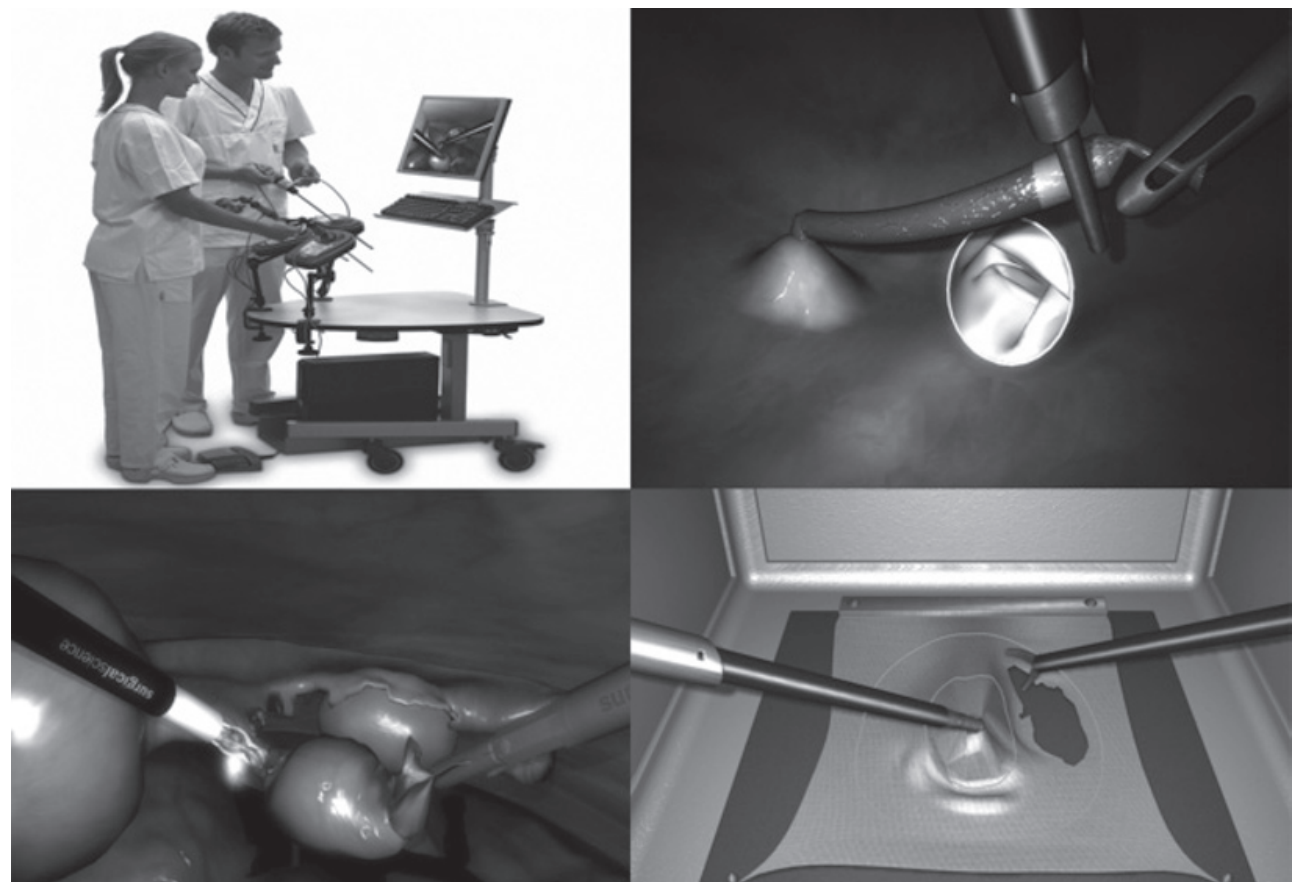

Figure 2. Virtual reality simulation (images provide by Surgical Science ${ }^{\mathrm{rm}}$ ).

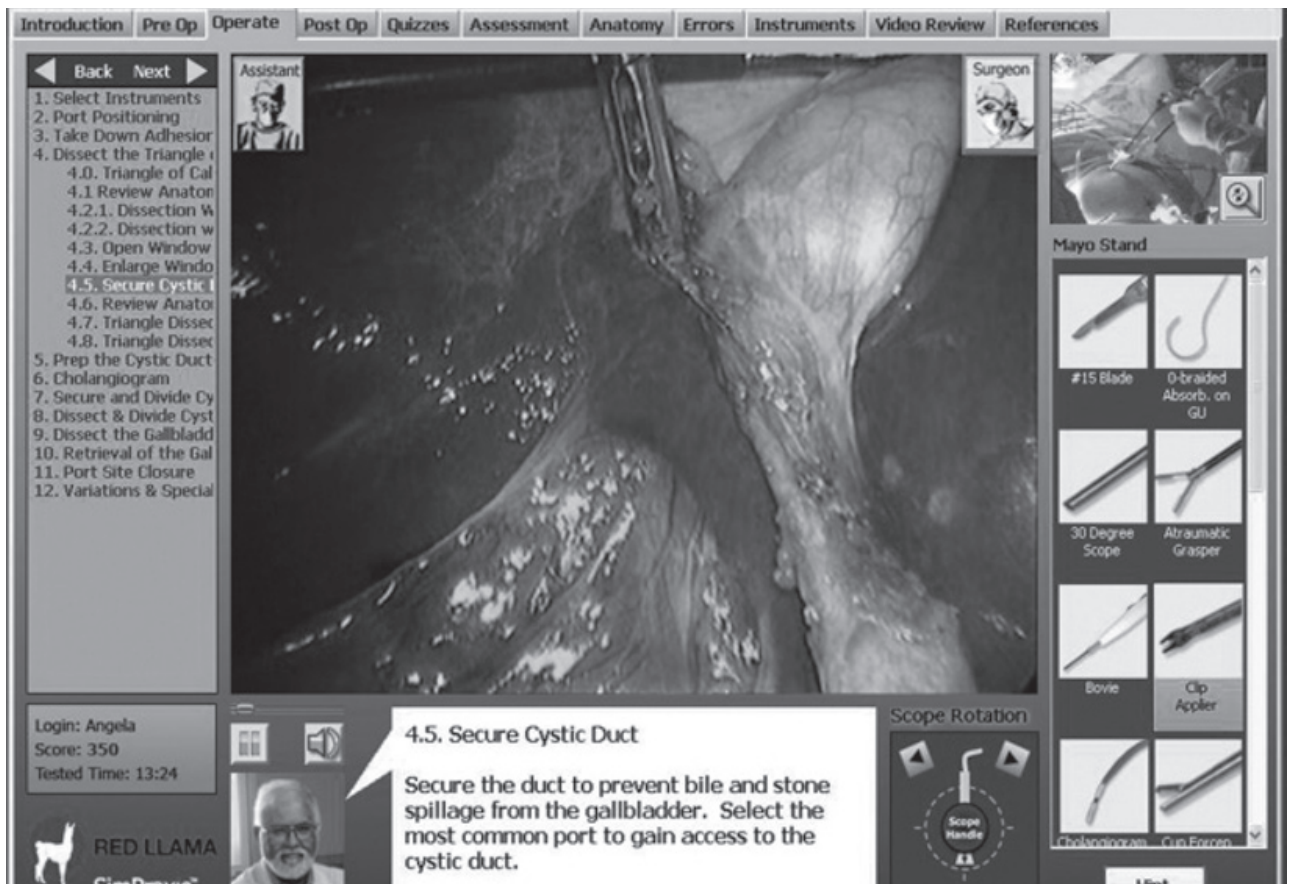

Figure 3. Laparoscopic Cholecystectomy e-training program (image provided bu Redllamatech ${ }^{\circ}$ ). 


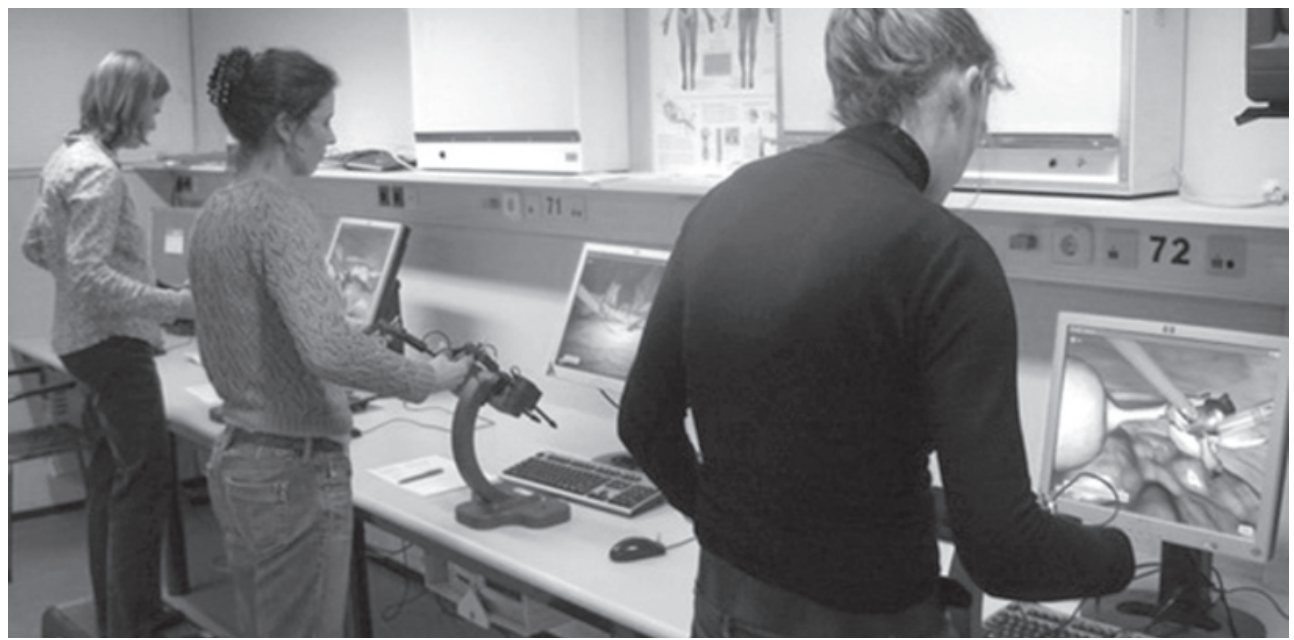

Figure 4. Virtual reality skills centre for training MIS (UMC Utrecht, the Netherlands).

6. Schout BM, Muijtjens AM, Hendrikx AJ, Ananias HJ, Dolmans VE, Scherpbier AJ, Bemelmans BL. Acquisition of Flexible Cystoscopy Skills on a Virtual Reality Simulator by Experts and Novices. BJU Int 2010;105:234-9.

7. Bajka M, Tuchschmid S, Fink D, Szekely G, Harders M. Establishing Construct Validity of a Virtual-Reality Training Simulator for Hysteroscopy Via a Multimetric Scoring System. Surg Endosc 2010;24:79-88.

8. Ahmed K, Keeling AN, Fakhry M, Ashrafian H, Aggarwal R, Naughton PA, Darzi A, Cheshire N, Athanasiou T, Hamady M. Role of Virtual Reality Simulation in Teaching and Assessing Technical Skills in Endovascular Intervention. J Vasc Interv Radiol 2010;21:55-66.

9. Larsen CR, Soerensen JL, Grantcharov TP, Dalsgaard T, Schouenborg L, Ottosen C, Schroeder TV, Ottesen BS. Effect of Virtual Reality Training on Laparoscopic Surgery: Randomised Controlled Trial. BMJ 2009;338:b1802.

10. Thijssen AS, Schijven MP. Contemporary Virtual Reality Laparoscopy Simulators: Quicksand or Solid Grounds for Assessing Surgical Trainees? Am J Surg 2010;199:529-41.

11. Verdaasdonk EG, Dankelman J, Schijven MP, Lange JF, Wentink M, Stassen LP. Serious Gaming and Voluntary Laparoscopic Skills Training: a Multicenter Study. Minim Invasive Ther Allied Technol 2009;18: 232-8.

12. Dutch Health Care Inspectorate (IGZ 2007). Rapport Risico's minimaal invasieve chirurgie onderschat, kwaliteitssysteem voor laparoscopische operaties ontbreekt. www.igz.nl Accessed 30-8-2010. [Risks of minimally invasive surgery is underestimated, quality system for laparoscopic procedures].
13. Stassen LP, Bemelman WA, Meijerink J. Risks of Minimally Invasive Surgery Underestimated: a Report of the Dutch Health Care Inspectorate. Surg Endosc 2010;24:495-8.

14. Dutch Society of Simulation in Healthcare (DSSH). www.dssh.nl Accessed 30-8-2010.

15. Korndorffer JR, Jr., Clayton JL, Tesfay ST, Brunner WC, Sierra R, Dunne JB, Jones DB, Rege RV, Touchard CL, Scott DJ. Multicenter Construct Validity for Southwestern Laparoscopic Videotrainer Stations. J Surg Res 2005;128:114-9.

16. Munz Y, Kumar BD, Moorthy K, Bann S, Darzi A. Laparoscopic Virtual Reality and Box Trainers: Is One Superior to the Other? Surg Endosc 2004;18: 485-94.

17. Fundamentals of Laparoscopic Surgery Program (FLS). www.flsprogram.org Accessed 30-8-2010.

18. Ritter EM, Scott DJ. Design of a Proficiency-Based Skills Training Curriculum for the Fundamentals of Laparoscopic Surgery. Surg Innov 2007;14:107-12.

19. Fried GM, Feldman LS, Vassiliou MC, Fraser SA, Stanbridge D, Ghitulescu G, Andrew CG. Proving the Value of Simulation in Laparoscopic Surgery. Ann Surg 2004;240:518-25.

20. Al-Abed Y, Cooper DG. A Novel Home Laparoscopic Simulator. J Surg Educ 2009;66:1-2.

21. Aggarwal R, Moorthy K, Darzi A. Laparoscopic Skills Training and Assessment. Br J Surg 2004;91:1549-58.

22. Botden SM, Jakimowicz JJ. What Is Going on in Augmented Reality Simulation in Laparoscopic Surgery? Surg Endosc 2009;23:1693-700.

23. Lucas SM, Zeltser IS, Bensalah K, Tuncel A, Jenkins A, Pearle MS, Cadeddu JA. Training on a Virtual Reality Laparoscopic Simulator Improves Performance of an Unfamiliar Live Laparoscopic Procedure. J Urol 2008;180:2588-91. 
24. Kundhal PS, Grantcharov TP. Psychomotor Performance Measured in a Virtual Environment Correlates With Technical Skills in the Operating Room. Surg Endosc 2009;23:645-9.

25. Aggarwal R, Ward J, Balasundaram I, Sains P, Athanasiou T, Darzi A. Proving the Effectiveness of Virtual Reality Simulation for Training in Laparoscopic Surgery. Ann Surg 2007;246:771-9.

26. Conradi E, Kavia S, Burden D, Rice A, Woodham L, Beaumont C, Savin-Baden M, Poulton T. Virtual Patients in a Virtual World: Training Paramedic Students for Practice. Med Teach 2009;31:713-20.

27. World Electronic Book of Surgery (WebSurg). www.websurg.com Accessed 19-10-2010.

28. 'Simpraxis ${ }^{\mathrm{TM}}$ Laparoscopic Cholecystectomy Trainer'. www.redllamatech.com Accessed 30-8-2010.

29. Shane MD, Pettitt BJ, Morgenthal CB, Smith CD. Should Surgical Novices Trade Their Retractors for Joysticks? Videogame Experience Decreases the Time Needed to Acquire Surgical Skills. Surg Endosc 2008;22:1294-7.

30. Badurdeen S, bdul-Samad O, Story G, Wilson C, Down S, Harris A. Nintendo Wii Video-Gaming Ability Predicts Laparoscopic Skill. Surg Endosc 2010;24: 1824-8.

31. Bokhari R, Bollman-McGregor J, Kahoi K, Smith M, Feinstein A, Ferrara J. Design, Development, and Validation of a Take-Home Simulator for Fundamental Laparoscopic Skills: Using Nintendo Wii for Surgical Training. Am Surg 2010;76:583-6.

32. Schreuder HW, Verheijen RH. Robotic Surgery. BJOG 2009;116:198-213.

33. Seixas-Mikelus SA, Kesavadas T, Srimathveeravalli G, Chandrasekhar R, Wilding GE, Guru KA. Face Validation of a Novel Robotic Surgical Simulator. Urology 2010;76:357-60.

34. Burchard ER, Lockrow EG, Zahn CM, Dunlow SG, Satin AJ. Simulation Training Improves Resident Performance in Operative Hysteroscopic Resection Techniques. Am J Obstet Gynecol 2007;197:542-4.

35. Grogan EL, Stiles RA, France DJ, Speroff T, Morris JA, Jr., Nixon B, Gaffney FA, Seddon R, Pinson CW. The Impact of Aviation-Based Teamwork Training on the Attitudes of Health-Care Professionals. J Am Coll Surg 2004;199:843-8.

36. Leape LL, Berwick DM. Five Years After To Err Is Human: What Have We Learned? JAMA 2005;293: 2384-90.

37. Frank JR, Langer B. Collaboration, Communication, Management, and Advocacy: Teaching Surgeons New Skills Through the CanMEDS Project. World J Surg 2003;27:972-8.

38. European Society for Gynaecological Endoscopy (ESGE). www.esge.org Accessed 30-8-2010.

39. van Dongen KW, van der Wal WA, Rinkes IH, Schijven MP, Broeders IA. Virtual Reality Training for Endoscopic Surgery: Voluntary or Obligatory? Surg Endosc 2008;22:664-7.
40. Schijven MP, Jakimowicz J. The Learning Curve on the Xitact LS 500 Laparoscopy Simulator: Profiles of Performance. Surg Endosc 2004;18:121-7.

41. Reznick RK, MacRae H. Teaching Surgical SkillsChanges in the Wind. N Engl J Med 2006;355:2664-9.

42. Gallagher AG, Ritter EM, Champion H, Higgins G, Fried MP, Moses G, Smith CD, Satava RM. Virtual Reality Simulation for the Operating Room: Proficiency-Based Training As a Paradigm Shift in Surgical Skills Training. Ann Surg 2005;241:364-72.

43. McClusky DA, III, Smith CD. Design and Development of a Surgical Skills Simulation Curriculum. World J Surg 2008;32:171-81.

44. MacRae HM, Satterthwaite L, Reznick RK. Setting Up a Surgical Skills Center. World J Surg 2008;32: 189-95.

45. Schijven MP, Reznick RK, ten Cate OT, Grantcharov TP, Regehr G, Satterthwaite L, Thijssen AS, MacRae HM. Transatlantic Comparison of the Competence of Surgeons at the Start of Their Professional Career. Br J Surg 2010;97:443-9.

46. Stefanidis D. Optimal Acquisition and Assessment of Proficiency on Simulators in Surgery. Surg Clin North Am 2010;90:475-89.

47. Lewis CE, Tillou A, Yeh MW, Quach C, Hiatt JR, Hines OJ. Web-Based Portfolios: a Valuable Tool for Surgical Education. J Surg Res 2010;161:40-6.

48. Stefanidis D, Hope WW, Korndorffer JR, Jr., Markley S, Scott DJ. Initial Laparoscopic Basic Skills Training Shortens the Learning Curve of Laparoscopic Suturing and Is Cost-Effective. J Am Coll Surg 2010;210:436-40.

49. Rosser JC, Rosser LE, Savalgi RS. Skill Acquisition and Assessment for Laparoscopic Surgery. Arch Surg 1997;132:200-4.

50. Mettler L, Zuberi N, Rastogi P, Schollmeyer T. Role and Value of Laparoscopic Training Devices in Assessing Nondominant and Two-Handed Dexterity. Gynecol Surg 2006;3:110-4.

51. Kirby TO, Numnum TM, Kilgore LC, Straughn JM. A Prospective Evaluation of a Simulator-Based Laparoscopic Training Program for Gynecology Residents. J Am Coll Surg 2008;206:343-8.

52. Dayan AB, Ziv A, Berkenstadt H, Munz Y. A Simple, Low-Cost Platform for Basic Laparoscopic Skills Training. Surg Innov 2008;15:136-42.

53. Campo R, Reising C, van Belle Y, Nassif J, O'Donovan P, Molinas C. A Valid Model for Testing and Training Laparoscopic Psychomotor Skills. Gynecol Surg 2010;7:133-41.

54. Zheng B, Denk PM, Martinec DV, Gatta P, Whiteford $\mathrm{MH}$, Swanstrom LL. Building an Efficient Surgical Team Using a Bench Model Simulation: Construct Validity of the Legacy Inanimate System for Endoscopic Team Training (LISETT). Surg Endosc 2008;22:930-7. 
55. Arden D, Hacker MR, Jones DB, Awtrey CS. Description and Validation of the Pelv-Sim: a Training Model Designed to Improve Gynecologic Minimally Invasive Suturing Skills. J Minim Invasive Gynecol 2008;15:707-11.

56. Lentz GM, Mandel LS, Lee D, Gardella C, Melville J, Goff BA. Testing Surgical Skills of Obstetric and Gynecologic Residents in a Bench Laboratory Setting: Validity and Reliability. Am J Obstet Gynecol 2001;184:1462-8.

57. Black M, Gould JC. Measuring Laparoscopic Operative Skill in a Video Trainer. Surg Endosc 2006;20: 1069-71.

58. Kolkman W, van der Put M, Wolterbeek R, Trimbos J, Jansen F. Laparoscopic Skills Simulator: Construct Validity and Establishment of Performance Standards for Residency Training. Gynecol Surg 2008;5:109-14.

59. Clevin L, Grantcharov TP. Does Box Model Training Improve Surgical Dexterity and Economy of Movement During Virtual Reality Laparoscopy? A Randomised Trial. Acta Obstet Gynecol Scand 2008;87: 99-103.

60. Risucci D, Cohen JA, Garbus JE, Goldstein M, Cohen MG. The Effects of Practice and Instruction on Speed and Accuracy During Resident Acquisition of Simulated Laparoscopic Skills. Curr Surg 2001;58: 230-5.

61. Verdaasdonk EG, Stassen LP, Schijven MP, Dankelman J. Construct Validity and Assessment of the Learning Curve for the SIMENDO Endoscopic Simulator. Surg Endosc 2007;21:1406-12.

62. Pellen MG, Horgan LF, Barton JR, Attwood SE. Construct Validity of the ProMIS Laparoscopic Simulator. Surg Endosc 2009;23:130-9.

63. Strom P, Kjellin A, Hedman L, Johnson E, Wredmark T, Fellander-Tsai L. Validation and Learning in the Procedicus KSA Virtual Reality Surgical Simulator. Surg Endosc 2003;17:227-31.

64. Zhang A, Hunerbein M, Dai Y, Schlag PM, Beller S. Construct Validity Testing of a Laparoscopic Surgery Simulator (Lap Mentor): Evaluation of Surgical Skill With a Virtual Laparoscopic Training Simulator. Surg Endosc 2008;22:1440-4.

65. Larsen CR, Grantcharov T, Aggarwal R, Tully A, Sorensen JL, Dalsgaard T, Ottesen B. Objective Assessment of Gynecologic Laparoscopic Skills Using the LapSimGyn Virtual Reality Simulator. Surg Endosc 2006;20:1460-6.

66. Stefanidis D, Haluck R, Pham T, Dunne JB, Reinke T, Markley S, Korndorffer JR, Jr., Arellano P, Jones DB, Scott DJ. Construct and Face Validity and Task Workload for Laparoscopic Camera Navigation: Virtual Reality Versus Videotrainer Systems at the SAGES Learning Center. Surg Endosc 2007;21: 1158-64.
67. Schijven MP, Jakimowicz JJ, Carter FJ. How to Select Aspirant Laparoscopic Surgical Trainees: Establishing Concurrent Validity Comparing Xitact LS500 Index Performance Scores With Standardized Psychomotor Aptitude Test Battery Scores. J Surg Res 2004;121:112-9.

68. Buzink SN, Goossens RH, De RH, Jakimowicz JJ. Training of Basic Laparoscopy Skills on SimSurgery SEP. Minim Invasive Ther Allied Technol 2010; 19:35-41.

69. Iwata N, Fujiwara M, Kodera Y, Tanaka C, Ohashi N, Nakayama G, Koike M, Nakao A. Construct Validity of the LapVR Virtual-Reality Surgical Simulator. Surg Endosc 2011;25:423-8.

70. Martin JA, Regehr G, Reznick R, MacRae H, Murnaghan J, Hutchison C, Brown M. Objective Structured Assessment of Technical Skill (OSATS) for Surgical Residents. Br J Surg 1997;84:273-8.

\section{De auteurs:}

Dr. Henk W.R. Schreuder, gynaecoloog/oncoloog, divisie Vrouw en Baby, afdeling Voortplantingsgeneeskunde en Gynaecologie, Universitair Medisch Centrum, Utrecht. * Prof. Dr. S. Guid Oei, gynaecoloog, afdeling Obstetrie \& Gynaecology, Máxima Medisch Centrum, Veldhoven en faculteit Biomedische Technologie, Technische Universiteit, Eindhoven.*

Dr. Mario Maas, radioloog, afdeling Radiologie, Academisch Medisch Centrum, Amsterdam.*

Prof. dr. Jan C.C. Borleffs, internist en prodecaan Onderwijs en Opleiding, Universitair Medisch Centrum, Groningen.

Dr. Marlies P. Schijven, chirurg, afdeling Chirurgie, Academisch Medisch Centrum, Amsterdam en voorzitter van de Dutch Society for Simulation in Healthcare (DSSH). *

* Alle auteurs zijn lid van de Dutch Society for Simulation in Healthcare (DSSH) die tegelijkertijd als werkgroep Skills en Simulatietechnieken van de Nederlandse Vereniging voor Medisch Onderwijs fungeert.

Correspondentieadres:

Dr. H.W.R. Schreuder, divisie Vrouw en Baby, afdeling Voortplantingsgeneeskunde en Gynaecologie, UMC Utrecht, postbus 85500, kamer F05-126, 3508 GA Utrecht. Tel.: 0031(0)88-7556427; fax: 0031(0)88-7555433; e-mail:h.w.r.schreuder@umcutrecht.nl

Belangenconflict: geen gemeld

Financiële ondersteuning: geen gemeld 